\title{
Escrituras fílmicas en el escenario de la Transición. En torno a la legitimidad de la lucha armada
}

\author{
Fernando REDONDO NEIRA \\ Universidad de Santiago de Compostela \\ fernando.redondo@usc.es
}

\begin{abstract}
Resumen:
El atentado que acabó con la vida del almirante Carrero Blanco en 1973 supuso un hecho decisivo en los momentos finales del tardofranquismo. El filme de Gillo Pontecorvo, Operación Ogro (1979), recreó aquel acontecimiento desde la perspectiva del comando etarra que lo llevó a cabo. Su tono de thriller político y la indagación en la psicológica de los personajes, no fueron valorados positivamente por la crítica del momento, que acusó a su director de no haber comprendido la compleja realidad del País Vasco. Sin embargo, el verdadero debate se sitúa en la toma de postura en torno a la legitimidad de la lucha armada una vez que el proceso de la transición ha alcanzado ya el consenso constitucional.
\end{abstract}

Palabras clave: Transición; consenso; lucha armada; Pontecorvo

\section{Film Scripts in the scene of Spanish Transition to democracy. About the legitimacy of armed struggle}

\begin{abstract}
:
The terrorist attack that took the life of Admiral Carrero Blanco in 1973 was a decisive event in the final moments of late-francoism . Gillo Pontecorvo's film, Operation Ogre (1979), recreated that event from the perspective of ETA commando that carried it out. His tone of political thriller and the psychological inquiry into the characters weren't hightly valued by critics at the time, who accused the director of not understanding the complex reality of the Basque Country. However, the actual debate lies in taking a stand regarding the legitimacy of armed struggle once the transition process has already reached the constitutional consensus.
\end{abstract}

Key Words: Transition; consensus; armed struggle; Pontecorvo.

\section{Referencia normalizada:}

Redondo Neira, F. (2014): Escrituras fílmicas en el escenario de la transición. En torno a la legitmidad de la lucha armada. Historia y Comunicación Social. Vol. 19. Núm. Especial Marzo. Págs. 341-350.

Sumario: 1. Introducción. 2. Recepción crítica. 3. Dispositivo narrativo. 4. Relato histórico. 5. Conclusión 


\section{Introducción}

Situados ya en la recta final de la Transición, el director italiano Gillo Pontecorvo, quien ocupaba un lugar de privilegio en el santuario del cine político por La batalla de Argel (1965), estrena en las pantallas españolas Operación Ogro (1980), filme que reconstruye el atentado del almirante Carrero Blanco. La película había clausurado un año antes el Festival de Venecia y presentaba el atractivo de recrear, desde la óptica del comando terrorista que lo llevó a cabo, las circunstancias y los hechos que rodearon aquel acontecimiento que tanto impacto había causado en la opinión pública y que, de un modo u otro, iba a condicionar el final de la dictadura y el inicio de un nuevo tiempo histórico. Finalmente, no se cumplieron las expectativas creadas y el filme no satisfizo plenamente ni a la crítica ni al público. Nos proponemos ahora estudiar el lugar que ocupa este título en el escenario de la Transición. A la altura del 1980, año del estreno, ¿de qué modo se relaciona con la situación política en el País Vasco?, ¿qué supuso la irrupción del filme en este preciso estadio del proceso de la transición y de la construcción del consenso democrático? Buscaremos las respuesta mediante la revisión de la recepción del filme, a través de los textos críticos que generó, a partir de su puesta en relación con la historiografía que se ocupó de estudiar la transición de la dictadura a la democracia y con el análisis, finalmente, de cómo la estructura del relato se adapta a un discurso político y su puesta en imágenes.

Partiendo del fuerte impacto del suceso recreado en Operación Ogro, seguiremos aquí las propuestas metodológicas de Manuel Trenzado, con objeto de analizar el filme en tanto que discurso social y considerando, a su vez, que aquél se sitúa en uno de esos "momentos privilegiados de cambio en los que el espacio público mass-mediático adquiere mayor importancia política y trascendencia social" (Trenzado, 1999: 40). De cómo las películas asumen esa condición de discursos sociales que contribuyen a un mejor conocimiento de esta etapa histórica, como portadoras, además, de una mirada que arroja luz sobre las sensibilidades del momento, las mentalidades o los posicionamientos políticos, no cabe si no adoptar el objetivo expresado por quien, como Trenzado, se ocupó de abordar las relaciones entre cine y Transición democrática: "abordar las películas y el cine como escenario desde el que se perciben los procesos de modernización social y de reforma política que tienen lugar en la Transición" (Palacio, 2011: 14). En definitiva, los filmes, siempre permeables a los avatares de su tiempo, poseen esa cualidad de atraer hacía sí cuantos elementos constituyen el particular contexto histórico en el que surgen, siendo capaces, por tanto, de establecer contacto con los más diversos aspectos procedentes de las esferas de lo cultural, lo social o lo político. Constituye un punto de partida analítico ampliamente compartido por los especialistas el entender la escritura fílmica como imbricación entre los textos filmicos y aquellas otras prácticas o discursos ajenos a dichos textos pero inscritos en él. Desde autores como Christian Metz, siempre tan volcado hacia los aspectos lingüísticos y, sin embargo, capaz de advertir que el cine implica también considerar diversas significaciones sociales o humanas forjadas en otros ámbitos de la cultura (2002: 98), pasando por historiadores como Allen y Gomery, que consideran que el cine no es algo unidimensional, sino el punto de convergencia de distintas líneas de 
fuerza histórica (1995:36), u otros como Michèle Lagny, que se expresa en parecidos términos al asegurar que el objeto filme debe vincularse a la compleja red de relaciones que mantiene no sólo con otros objetos, sino también con otras prácticas culturales, económicas o institucionales (1997: 13).

Sobre el caso particular de la Transición en España, señalemos, finalmente, su enorme incidencia sobre la producción cultural de su tiempo, la urgencia que subyace en el tratamiento de los asuntos de actualidad, tal como corresponde, en palabras del ya citado Trenzado, a un "momento privilegiado"; un momento de cambio que supone también una socialización en los usos y comportamientos democráticos y en el que, en definitiva, difícilmente se podría dar la espalda a los decisivos acontecimientos que marcaron el período. Así lo supieron recoger Hernández Rubio y Pérez Rubio en su monografía sobre el cine de estos años:

(...) las peculiares circunstancias que atravesaba el país favorecieron la irrupción de la política en las pantallas, abordada de manera directa, reflexiva, metafórica, retrospectiva, etc. Nunca en la historia de nuestro celuloide esa dimensión había tenido tanto protagonismo y será raro que vuelva a tenerlo de ese modo (2004: 80)

\section{Recepción crítica}

La recepción crítica de Operación Ogro con motivo de su estreno comercial en 1980 ofrecía ya suficientes indicios del difícil encaje del filme en aquel preciso momento del desarrollo del proceso de la Transición. La revisión de aquellos textos críticos permite comprobar un evidente desajuste temporal, pues los hechos narrados ya no pueden ser recibidos de igual manera a como lo serían en 1973, año del atentado de Carrero Blanco. A ello habrá que añadir lo que será una constante en toda lectura que se haga de aquellos filmes que aborden el terrorismo etarra: lo incómodo de tratar un tema considerado tabú, la dificultad que supone abordar la representación fílmica de aquello que suscita una fuerte controversia política y que genera una dolorosa fragmentación social. Cuantos análisis se hagan de la presencia de ETA en el cine citarán sistemáticamente esta cuestión. Valga a modo de ejemplo: "Pocos realizadores se han atrevido con el conflicto vasco en contraste con la ingente cantidad de películas que trataron el tema de la guerra civil" (Marcos Ramos, 2009: 147). La autora aduce a continuación que quizá se deba a la falta de la distancia necesaria que requiere el tema. En el diario de referencia del País Vasco, El Correo Español-El Pueblo Vasco, Francisco Echeverría elogia la valentía de Pontecorvo al haberse ocupado de un tema tan conflictivo, aunque, finalmente, la película no haya convencido ni gustado a casi nadie, a lo que habría que añadir el fracaso que resulta de no haberse decantado claramente ni por el testimonio político ni por el thriller policiaco (Echeverría, 1980: 7). Por su parte, el corresponsal en Bilbao de El País, Patzo Unzueta, adelanta las razones que explican esta mala acogida, y que se resume en la frustración de las expectativas generadas, pues el público no reconoce en la pantalla la realidad de los hechos, como tampoco percibe la necesaria referencia al transfondo social ("no hay coro en 
esta tragedia"), para terminar acusando al cineasta de rapiña, de manipulación y, en relación con sus filmes anteriores, de claudicación. El cronista destaca además que el diario Egin no incluye el filme en su lista semanal de películas recomendadas, donde sí figura la El proceso de Burgos, de Imanol Uribe (Unzueta,1980: 56). ${ }^{1}$ En el mismo diario, y tras su estreno en Madrid, Jesús Fernández Santos señala que el cine, a diferencia de la Historia, no puede esperar, si bien el tratamiento de temas de actualidad puede dar lugar a un cierto desajuste entre la verdad y lo verosímil, ejemplificado en la poca verdad que transmite un actor como José Sacristán, tan conocido entonces por otro tipo de filmes (Fernández Santos, 1980: 38). Modestísimo artefacto sin onda política, sin auténtica tensión y sin vibración humana: así califica el filme la crítica de $A B C$, donde se la considera una película fallida incluso para quienes buscaban en ella "un motivo de apoyo, de justificación moral y política, para los posteriores vandalismos criminales de los terroristas de ETA" (Crespo 1980: 61). ${ }^{2}$ El crítico de $Y a$, Pascual Cebollada, destaca el esfuerzo que el filme dedica a resaltar la dimensión psicológica de los protagonistas no alcanza para lograr el exigible interés humano, y que la película sobre aquellos hechos está aún por hacer (Cebollada, 1980: 43). La misma indefinición será puesta de relieve en la apreciación crítica publicada en La Vanguardia, indefinición que se extiende aquí al difícil encaje genérico y al intento de contentar a todos los grupos políticos, lo que redunda en un filme "cauteloso por las ardientes connotaciones que el asunto comporta” (Maso, 1980: 65).

En lo que respecta a las publicaciones especializadas, la desacertada estrategia narrativa desplegada, que dificultaba el adecuado tratamiento exigido por lo complejo del tema, se unía a las críticas ya reseñadas en torno al intento imposible de no herir sensibilidades y la ocasión desaprovechada de construir un más más potente artefacto cinematográfico. Así, la reseña publicada sin firma en Cinema 2002 llamaba la atención sobre la ausencia de una mayor perspectiva histórica, necesaria para engarzar los hechos narrados con las complejísimas situaciones en las que se enmarcan dichos hechos (Cinema 2002, 1980: 11).

En estas críticas, como en otras menciones que se harán al filme por parte de historiadores del cine, se sugiere, de un modo más o menos explícito según los casos, lo incómoda que resulta aquella lectura de Operación Ogro que conduciría a otorgar un implícito reconocimiento a la contribución que la organización terrorista hace a la liquidación del franquismo. Así figura, en cierto modo, en la crítica de Esteve Riambau en Dirigido por, para quien la tesis que la película busca defender, la de que el terrorismo estaría justificado en una dictadura pero no en el contexto democrático, no se ajusta al discurso narrativo desplegado, que busca sobre todo la expresión de la espectacularidad y el suspense de la acción terrorista (Riambau, 1980: 74)3.

La lectura de tan controvertido título ${ }^{4}$ se centrará finalmente, en el terreno de la legitimidad o no de la lucha armada, tal como lo plantea Santos Zunzunegui en Contracampo. Asegura allí que la película vendría a poner en imágenes la tesis de que la lucha armada no tendrá cabida en una democracia de corte europea, y que otra cosa habría que decir bajo un régimen fascista. Según Zunzunegui, la película no podía dejar de adoptar una postura concreta dada la rigurosa contemporaneidad del 
tema, en contra, por cierto, de la supuesta indefinición que hemos venido reseñando, pues la lucha armada de ETA no se había detenido y el proceso analizado en el filme seguía desarrollándose ante los ojos del espectador. El autor criticará, por otro lado, la ausencia de la necesaria conexión entre los pares lucha armada / fascismo y lucha política / democracia formal (Zunzunegui, 1980, 63).

En efecto, en la línea de lo apuntado por Zunzunegui, entre 1973 año del atentado, y 1979/80, año de estreno del filme, tiene lugar una decisiva evolución de ETA, que habría que vincular, por supuesto, al nuevo tiempo del consenso: la escisión entre ETA militar y ETA político- militar, con la consiguiente irrupción de la organización política Euskadiko Ezkerra; es decir, la división entre los partidarios de continuar con la práctica de la violencia y aquellos otros que prefieren recurriir a la acción política. Ambas posturas estarán, entonces, encarnadas en los personajes de Xabi, a cargo de Eusebio Poncela, e Izarra, interpretado por Gian Maria Volonté. En esta confrontación de posturas interviene también la pareja de Xabi, (Amaiur, Ángela Molina) quien, con cierto carácter premonitorio, le reprocha que prefiera luchar hasta las últimas consecuencias, aun a costa de provocar con ello un golpe de estado. Este será, por tanto, el exacto escenario en el que irrumpe Operación Ogro, como lo supo explicar Santiago de Pablo, obviando lo que pareciera evidente en una primera lectura:

(...) Operación Ogro no plantea tanto un apoyo a HB o a ETA militar, sino más bien a la vía negociadora entonces representada por Euskadiko Ezkerra. Es decir, la diferencia entre una ETA buena (la del franquismo) y una mala (la de la etapa democrática). (de Pablo, 1998: 183).

\section{Dispositivo narrativo}

La preparación y ejecución del atentado, materia narrativa que ocupa la parte central del relato, se dispone en una estructura diegética enmarcada por sendas secuencias situadas en el presente de 1978 y que muestran los destinos disímiles que seguirán los integrantes del comando terrorista. ${ }^{5}$ Aquel corpus central corresponde entonces a dos flashback que emergen a partir del cierre del plano sobre el rostro en actitud grave y evocadora de Xabi e Izarra. Sobre el primero se focaliza, de este modo, todo lo concerniente al trabajo de preparación del atentado más la puesta en imágenes de la represión sufrida en la juventud; sobre el segundo se situará la ejecución final de la acción terrorista. La impulsividad y sangre fría de Xabi se opone así a la prudencia y el talante reflexivo de Izarra, quien finalmente encarnará esa otra vía de lucha por la causa representada por ETA político- militar y su derivación política, Euskadiko Ezkerra.

La experiencia de la clandestinidad, la vivencia extrema de la preparación y ejecución de un atentado y la recreación ficcional de un acontecimiento real se trasladan al espectador mediante la adopción de un punto de vista que otorga la mirada y la voz a los terroristas. Este sencillo dispositivo enunciativo, tan habitual en estas ficciones 
sobre hechos reales construidas desde la espectacularidad y el tono épico y por el cual se articulan eficaces mecanismos de identificación, logran así la gratificación del sujeto-espectador, al que se invita a conocer los hechos desde dentro. Se contribuye, así, en definitiva, a la plena inmersión en el relato, que el espectador deberá validar cono verosímil.

En relación con esta específica modalización del relato fílmico, cabe citar una película con la que mantiene una cierta relación, el documental ;Arriba España!, una producción francesa de 1975 dirigida por José María Berzosa, cineasta español exiliado en aquel país, donde sí comparecen los verdaderos etarras que participaron en el atentado de Carrero. Operación Ogro llevará esto mismo al terreno de la ficción, de modo que bien podría considerarse que el relato fílmico emerge de aquel otro relato oral de los testimonios de espaldas a la cámara de ;Arriba España!, poniendo así en imágenes alguna de las declaraciones más impactantes de aquellos: "Vimos a Carrero Blanco saliendo de su casa y eso es una cosa que impresiona mucho, la última vez que ves a una persona cuando sabes que poco después te la vas a llevar por delante". En otro orden de cosas, de la comparativa entre ambos filmes se deduciría una cierta relación de simetría. Primeramente, pasar de un título a otro supone el traslado de lo documental a lo ficcional en el tratamiento del mismo acontecimiento (la película de Berzosa se ocupa, no obstante, del más amplio período de agonía del franquismo). Después, recordemos que la célebre secuencia de la voladura del coche de Carrero en la película de Pontecorvo será luego profusamente utilizada en todo tipo de reportajes y documentales sobre la Transición, habiendo quedado como la imagen definitiva de aquel acontecimiento, como se ha ocupado de destacar Malalana Ureña (2006: 2010)

Más allá de esta representación, presentada como veraz, de un capítulo destacado de la historia reciente, quizá su interés esté en el exterior del propio texto, en ese contexto sociopolítico del que emanaba. La reflexión que Operación Ogro suscita gira en torno a cómo una película alude en 1979 a un determinado hecho de 1973, con lo que supone situarse a ambos extremos de ese arco temporal que en apenas seis años vivió la desaparición de una dictadura y la emergencia de una democracia que, en el año de producción del filme, había alcanzado un punto de (aparente) no retorno una vez alcanzado el consenso constitucional. En el transcurso de esos pocos años, el país había cambiado sustancialmente, lo cual de algún modo tuvo que repercutir en la recepción de un filme, que también recoge la significativa evolución que, a su vez, había registrado la banda terrorista ETA. ¿Cómo se recibiría, entonces, un filme político que abordaba un tema como éste en la España de 1979?

\section{Relato histórico}

Para conocer el alcance político que podría esperarse de la acogida que tendría este filme, convendría primero acudir al relato de la Historia. De entrada, habría que recordar que los especialistas niegan que el asesinato del almirante contribuyera a la 
llegada de la democracia, aunque sí aceleró la agonía final del régimen. Por otro lado, en relación con ETA, historiadores como Álvaro Soto consideran que, sin haberlo buscado, aquella salió reforzada del atentado como símbolo de resistencia a la dictadura "con el visto bueno de la oposición antifranquista que celebró por omisión el asesinato del presidente en función de su relevancia" (Soto 2005: 135). Yendo a lo concreto, puede observarse también que determinados aspectos que conforman la realidad de los hechos se trasladarán a la ficción, como la pretensión de Xabi de matar a Carrero sin ocuparse de a quién podría beneficiar, en respuesta a la inquietud de Luken de si no estarán dejándoles hacer (los servicios secretos, la CIA). Ello viene recogido por Javier Tusell y Genoveva Queipo de Llano cuando, al tratar las supuestas conspiraciones que pudieran estar detrás del magnicidio aseguran:

La propia ETA no pensó demasiado en las consecuencias de lo que iba a hacer, sino que se guió por el simple vértigo de la acción y no por un alambicado juicio sobre las consecuencias de la desaparición del almirante. (2003: 50).

Asimismo, la colaboración entre ETA y el movimiento obrero que muestra la película, también figura en el libro de los citados historiadores, quienes indican que la preparación se benefició de las facilidades materiales y humanas dadas por algunos heterodoxos del comunismo ${ }^{6}$.

Un filme como Operación Ogro recoge en su propio planteamiento discursivo algunos de los hechos, personajes o evoluciones que ayudan a comprender el período por el cual transita. Desde 1973, cuando asistimos a los últimos estertores del franquismo, de los que la muerte de Carrero Blanco, motivo central del filme, son la más clara referencia, hasta 1980, año del estreno comercial, la Transición ha completado ya una parte sustancial de su recorrido (a falta de sonados incidentes), una vez logrado el decisivo consenso constitucional. Nuevos fenómenos sociales comparecen ahora en el espacio público, de los que se ocuparán otros filmes y dando así la impresión de que Operación Ogro ya está fuera de lugar. Nos referimos al llamado desencanto, al que seguirá la idea de crisis (más individual que colectiva), la aparición de una cierta acracia social y un mayor individualismo o, en general, el creciente desinterés por la política ${ }^{7}$.

La participación del filme de Pontecorvo en alguno de los debates de su tiempo se reducirá entonces al controvertido asunto de la legitimidad de la lucha armada. La propia disposición del relato en sendos flashback busca trazar la evolución experimentada por ETA. Los distintos planos temporales que articulan la narración permiten ir dando cuenta de aquella evolución, aludir a las escisiones sufridas por la banda y confrontar la divergencia de planteamientos entre permanecer en la lucha hasta el final o emplearse sólo en las labores políticas. A esto último aluden las apelaciones al diálogo de Amaiur e Izarra, sus intentos de cerrar viejas heridas y su deseo de empezar de nuevo en un tiempo nuevo, lo cual bien podría trasladarse a la causa general de la transición a la democracia. 


\section{Conclusión}

En conclusión, y por cuanto llevamos dicho, para finalizar la tarea de situar este filme en el escenario de la transición política podemos acudir al célebre binomio reforma / ruptura, binomio que no por socorrido, y probablemente reduccionista, deja de demostrar su operatividad. La película de Pontecorvo ocuparía por tanto el espacio de la reforma, así como el filme con el que la hemos relacionado, ;Arriba España, apuesta decididamente por la ruptura, como queda nítidamente reflejado en el plano final en el que vemos al príncipe Juan Carlos echando una palada de tierra a la fosa de Carrero Blanco mientras escuchamos su voz jurando fidelidad a los principios del Movimiento, tratando así, paradójicamente, de conjurar toda opción de continuidad. Operación Ogro, por el contrario, pone en imágenes la crisis definitiva de la legitimidad del recurso a la la lucha armada, se expresa a favor del cambio dentro de un orden, de la apelación al diálogo y de la búsqueda del consenso.

Una cita de Javier Tusell podría sintetizar con precisión lo que dicho período representó, y a la que podemos someter la propia lectura que se haga de Operación Ogro tal como puede comprobarse mediante el análisis de sus estrategias narrativas y a la luz, a su vez, de los comentarios críticos que en su día suscitó: "Resultó una ruptura por procedimientos reformistas o una reforma tan profunda que hizo desaparecer radicalmente lo reformado" (Tusell, 2007: 46).

\section{Bibliografía:}

ALLEN, R.C.; GOMERY, D. (1995). Teoría y práctica de la historia del cine. Barcelona: Paidós.

HERNÁNDEZ RUIZ, J: PÉREZ RUBIO, P. (2004). Voces en la niebla. El cine durante la Transición española (1973-1982). Barcelona: Paidós.

LAGNY, M. (1997). Cine e historia: problemas y métodos en la investigación cinematográfica. Barcelona: Bosch, 1997.

MALALANA UREÑA, A. (2006). "ETA y el cine. Las fuentes de información de los profesionales del cine". En: Revista General de Información y Documentación, $\mathrm{n}^{\circ}$ 16, Madrid: Universidad Complutense. p. 195-216.

MARCOS RAMOS, M. (2009). "ETA y el cine: un territorio en conflicto". En MARTÍN ESCRIBÁ, A.; SÁNCHEZ ZAPATERO, J. (eds.) (2009). Geografias en negro. Escenarios del género criminal. Barcelona: Montesinos. p. 147-171

METZ, CH. (2002). Ensayos sobre la significación en el cine, Barcelona: Paidós.

MONTERDE, J. E. (1993): Veinte años de cine español (1973-1992): un cine bajo la paradoja. Barcelona: Paidós.

DE PABLO, S. (1998). "El terrorismo a través del cine. Un análisis de las relaciones entre cine, historia y sociedad en el País Vasco". En: Comunicación y Sociedad, Volumen XI, nº 2,Pamplona: Universidad de Navarra. p. 177 - 200. 
PALACIO, M. (2011). "Introducción". En PALACIO, M. (Ed.) (2011). El cine y la transición política en España (1975-1982). Madrid: Biblioteca Nueva. p. 7-18.

ROLDÁN LARRETA, C. (2001). "Una apuesta suicida; ETA en el cine de Euskadi”. En: Ikusgaiak, $n^{\circ}$ 5, Pamplona: Sociedad de Estudios Vascos. p. 181-205.

SOTO CARMONA, A. (2005): ¿Atado y bien atado? Institucionalización y crisis del franquismo. Madrid: Biblioteca Nueva.

TORRADO, M.; RÓDENAS, G. (2009). "La figura del terrorista en el cine español. De la lucha justificada a la cotidianidad”. En: FERNÁNDEZ TOLEDO, P. (coord.) (2009). Rompiendo moldes. Discursos, géneros e hibridación en el siglo XXI. Sevilla: Comunicación Social. p. 160-185.

TRENZADO ROMERO, Manuel (1999): Cultura de masas y cambio político: El cine español de la transición. Madrid: CSIC.

TUSELL, J.; QUEIPO DE LLANO, G. (2003): Tiempo de incertidumbre. Carlos Arias Navarro entre el franquismo y la Transición (1973 - 1976). Barcelona: Crítica.

TUSELL, J. (2007): La transición a la democracia: (España, 1975-1982). Madrid: Espasa Calpe.

6.1 Revistas y magazines

Cinema 2002, $\mathrm{n}^{\circ}$ 64, junio 1980

Contracampo, $\mathrm{n}^{\circ} 13$, pp. 62- 63.

Dirigido por, $\mathrm{n}^{\circ} 74$, junio-julio 1980

Triunfo, $\mathrm{N}^{\mathrm{o}}$ 907, 14-06-1980

\subsection{Diarios}

$A B C, 30-05-1980$

El Correo Español-El Pueblo Vasco, 01-05-1980

El País, 11-05-1980

El País, 15-05-1980

La Vanguardia, 05-06-1980

La Vanguardia, 19-12-1993

Ya, 14-05-1980

\section{Notas}

1 Se cita también a Alfonso Sastre, quien había puesto reparos a una primera versión del guión. Además, según testimonio de su mujer, Eva Forest, autora del libro en el que se inspira el filme, Operaión ogro, el dramaturgo había presentado al etarra Argala a Pontecorvo (La Vanguardia, 19-12-1993).

2 La benevolencia con que es vista la figura del terrorista será puesta de relieve en textos analíticos posteriores. Se mencionará, por ejemplo, la pretensión de que se integren en el discurso de reconciliación nacional, haciendo ello extensible a un filme de 1976 que trata el mismo tema, Comando Txikia, 
de José Luis Madrid (Torrado y Ródenas, 2009: 162), o bien que sean vistos con el halo romático del héroe justiciero que luha contra la tiranía fascista (Roldán, 2001: 182)

3 En una entrevista publicada en este mismo número de Dirigido por, Pontecorvo rebatía estas críticas al afirmar que la película trataba sobre un atentado y no sobre ETA (Gómez Olea 1980: 48)

4 Recordemos que algunos cines que exhibían la cinta fueron atacados por elementos de la extrema derecha, tal como refiere José Enrique Monterde (1993): Veinte años de cine español (1973-1992): un cine bajo la paradoja. Barcelona: Paidós, P. 71.

5 Un tercer desvío temporal nos conduce a la adolescencia de los protagonistas para dar cuenta de la toma de conciencia y la adhesión a la causa del independentismo vasco.

6 En la citada entrevista, Eva Forest acusa al director, con quien asegura también haberse entrevistado, de dejarse influenciar por el Partido Comunista Italiano. Afirma, a su vez, que los poli-milis hablaron con Pontecorvo y le transmitieron falsedades que, tal como se deduce de sus palabras, se trasladarán al filme.

7 En un irónico texto publicado en Triunfo, Manuel Vicent aprovecha la coincidencia en las carteleras de la película de Pontecorvo con Opera prima, de Fernando Trueba, para describir un tiempo nuevo en el que la juventud comienza a desentenderse de los asuntos políticos y se entrega a una actitud ácrata que la separa irremediablemente de las generaciones anteriores (Vicent 1980: 36).

\section{El autor}

Fernando Redondo Neira. Doctor en Ciencias de la Información. Profesor del área de comunicación audiovisual de la facultad de Ciencias de la Comunicación de la Universidad de Santiago de Compostela (USC). Autor del libro Carlos Velo. Itinerarios do documental nos anos trinta y coordinador/editor del volumen Ciudadanía y documental. Miembro de la Asociación Española de Historiadores del Cine (AEHC) y de la Asociación Galega de Investigadores da Comunicación (AGACOM). Premio Mari Luz Morales de Ensayos Cinematográficos, otorgado en 2007 por la Consellería de Cultura de la Xunta de Galicia. 